\title{
Diagnosis and Management of Rectal Neuroendocrine Tumors
}

\author{
Shreya Chablaney, Zachary A. Zator and Nikhil A. Kumta \\ Division of Gastroenterology, Icahn School of Medicine at Mount Sinai, New York, NY, USA
}

The incidence of rectal neuroendocrine tumors (NETs) has increased by almost ten-fold over the past 30 years. There has been a heightened awareness of the malignant potential of rectal NETs. Fortunately, many rectal NETs are discovered at earlier stages due to colon cancer screening programs. Endoscopic ultrasound is useful in assessing both residual tumor burden after retrospective diagnosis and tumor characteristics to help guide subsequent management. Current guidelines suggest endoscopic resection of rectal NETs $\leq 10 \mathrm{~mm}$ as a safe therapeutic option given their low risk of metastasis. Although a number of endoscopic interventions exist, the best technique for resection has not been identified. Endoscopic submucosal dissection (ESD) has high complete and en-bloc resection rates, but also an increased risk of complications including perforation. In addition, ESD is only performed at tertiary centers by experienced advanced endoscopists. Endoscopic mucosal resection has been shown to have variable complete resection rates, but modifications to the technique such as the addition of band ligation have improved outcomes. Prospective studies are needed to further compare the available endoscopic interventions, and to elucidate the most appropriate course of management of rectal NETs. Clin Endosc 2017;50:530-536

Key Words: Rectal neuroendocrine tumor; Endoscopic ultrasound; Endoscopic mucosal resection; Endoscopic submucosal dissection

\section{INTRODUCTION}

Neuroendocrine tumors (NETs) of the gastroenteropancreatic system have varied behaviors, clinical presentations, and prognoses depending on their anatomic location. As such, their diagnosis and management strategies differ greatly. According to multiple analyses of the Surveillance, Epidemiology, and End Results (SEER) database over time from the National Cancer Institute, the age-adjusted incidence of rectal NETs from 1973 to the 2000s has increased by almost ten-fold. ${ }^{1-6}$ It is thought that this rise is due to a heightened awareness of the disease process in conjunction with an improvement in colorectal cancer preventative screening, as

Received: August 22, 2017 Revised: November 15, 2017

Accepted: November 19, 2017

Correspondence: Nikhil A. Kumta

Division of Gastroenterology, Icahn School of Medicine at Mount Sinai, One Gustave L. Levy Place, Box 1069, New York, NY 10029, USA

Tel: +1-212-241-7535, Fax: +1-212-241-2276,

E-mail: Nikhil.Kumta@mountsinai.org

cc This is an Open Access article distributed under the terms of the Creative Commons Attribution Non-Commercial License (http://creativecommons.org/ licenses/by-nc/3.0) which permits unrestricted non-commercial use, distribution, and reproduction in any medium, provided the original work is properly cited. an increasing proportion of these detected rectal neoplasms have been low grade. ${ }^{5,6}$ The malignant potential of these NETs has been well appreciated since publication of the 2010 World Health Organization (WHO) classification. ${ }^{6}$ Given the rise in early disease detection, many minimally invasive endoscopic methods for resection have emerged. However, there remains a relative paucity of robust literature comparing these diagnostic and therapeutic endoscopic interventions in the management of rectal NETs. This review of the literature will discuss the available options for endoscopic therapeutic intervention, the role of endoscopic ultrasound (EUS) in pre-intervention planning, and salvage therapy for patients with rectal NETs $\leq 10 \mathrm{~mm}$ in size.

A thorough literature search was performed to assess pertinent citations found in MEDLINE for the keywords: 'rectal neuroendocrine', 'rectal,' 'rectum', 'carcinoid,' 'neuroendocrine tumor,' 'NET,' 'endoscopic, 'mucosal,' 'submucosal, 'resection,' 'dissection,' 'EMR, 'ESD', 'ultrasonography,' 'EUS, 'endoscopy', 'transanal,' 'endoscopic microsurgery,' 'salvage, 'therapy', and 'surgery'. 


\section{CLINICAL FEATURES}

Macroscopically, rectal NETs appear as smooth, round, polypoid lesions with normal overlying mucosa that are usually found within $5-10 \mathrm{~cm}$ from the anal verge (Fig. 1). According to SEER data, there is a slight male predominance and mean age at diagnosis is 57 years. ${ }^{1,4}$ Rectal NETs have a higher incidence and prevalence in both African American and Asian populations as compared to Caucasians. ${ }^{1,4,8}$ NETs of rectal origin almost never present with the traditional "carcinoid syndrome" symptoms characterized by episodic cutaneous flushing and diarrhea. ${ }^{8}$ They are often asymptomatic, but approximately $50 \%$ can present with rectal bleeding, changes in bowel habits, unexplained weight loss, or pain.,10

\section{STAGING AND GRADING}

Rectal NETs are classified both by stage and grade. Guide- lines for grading have been proposed by the WHO in 2010, and separate rectal NETs into three categories based on both mitotic count and Ki67 index: Low Grade $(\mathrm{G} 1)=<2$ mitoses/10 high power fields (HPFs) AND $\leq 2 \%$ Ki67 index; Intermediate Grade $(\mathrm{G} 2)=2-20$ mitoses $/ 10$ HPFs OR 3\%-20\% Ki67 index; or High Grade (G3) $=>20$ mitoses/10 HPFs OR $>20 \%$ Ki67 index. ${ }^{3,8}$ Both the American Joint Cancer Commission (AJCC) and the European Neuroendocrine Tumor Society published identical tumor, node, metastasis (TNM) staging recommendations in the same time frame, which is corroborated by the North American Neuroendocrine Tumor Society. ${ }^{8}$ This TNM staging system incorporates tumor size, depth/invasion, and metastatic spread (Table 1). ${ }^{11}$

\section{PROGNOSIS}

According to the SEER database, rectal NETs have the best median overall survival (after appendiceal neoplasms)

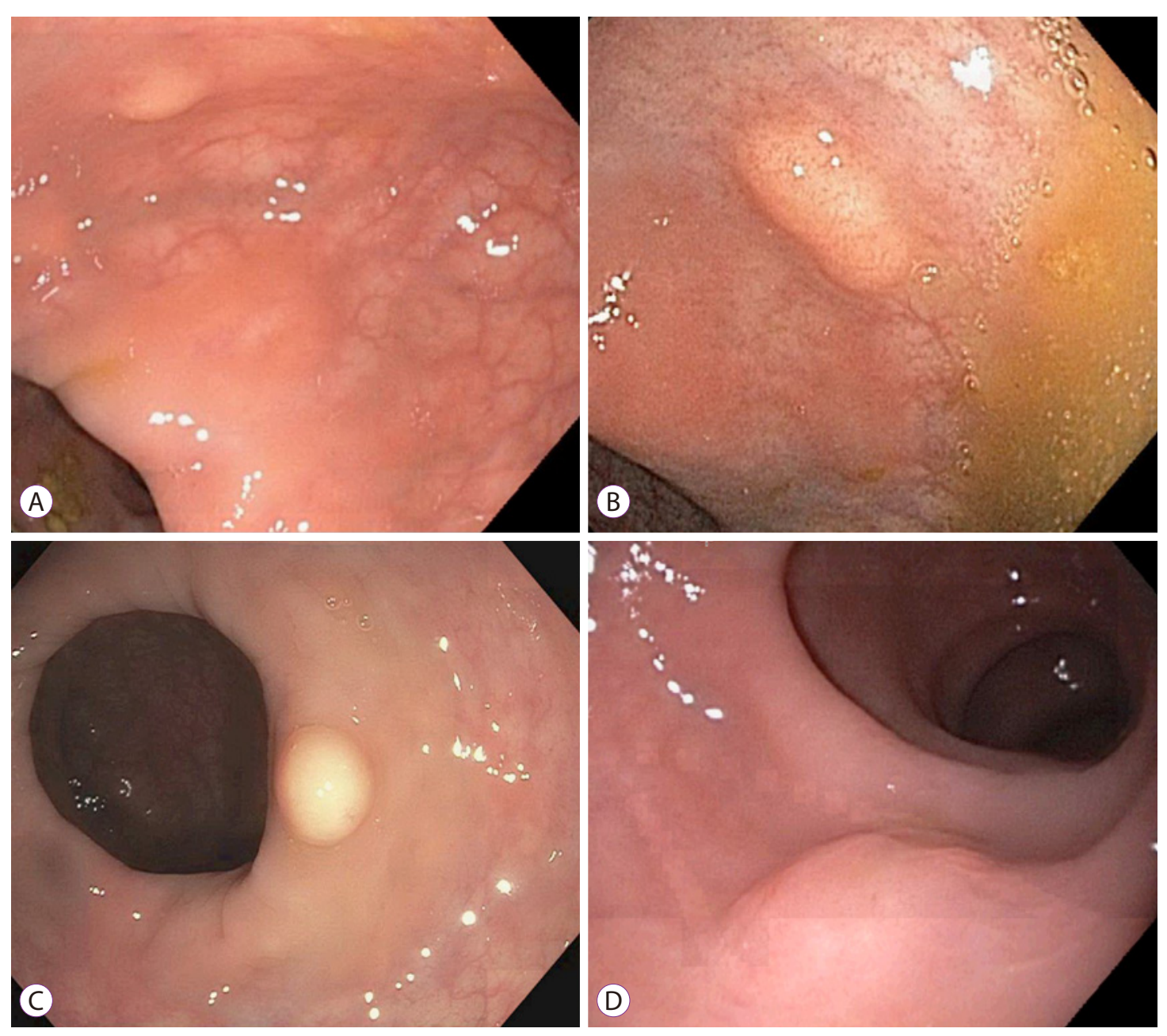

Fig. 1. Endoscopic views of rectal neuroendocrine tumors. (A), (B), (C), and (D) show appearance of rectal neuroendocrine tumors in various patients. 
Table 1. TNM Staging Neuroendocrine Tumors of the Colon and Rectum

\begin{tabular}{ll}
\hline Primary tumor $(\mathrm{T})$ \\
TX & Primary tumor cannot be assessed \\
T0 & No evidence of primary tumor \\
T1 & $\begin{array}{c}\text { Tumor invades lamina propria or submucosa; } \\
\text { size }<2 \mathrm{~cm}\end{array}$ \\
T1a & Tumor size $<1 \mathrm{~cm}$ \\
T1b & Tumor size $1-2 \mathrm{~cm}$ \\
T2 & Tumor invades muscularis propria or size \\
& $>2$ cm with invasion of lamina propria or \\
T3 & Tubmucosa \\
& propria into the subserosal tissue without \\
& penetration of overlying serosa \\
T4 & Tumor invades peritoneum or other organs \\
Regional lymph nodes $(\mathbf{N})$ & Regional lymph nodes cannot be assessed \\
NX & No regional lymph node metastasis \\
N0 & Regional lymph node metastasis \\
N1 &
\end{tabular}

Distant metastases (M)

$\begin{array}{ll}\text { M0 } & \text { No distant metastasis } \\ \text { M1 } & \text { Distant metastasis }\end{array}$

\begin{tabular}{llll}
\multicolumn{1}{l}{ Anatomic Stage } & & & \\
Stage 0 & Tis & N0 & M0 \\
Stage I & T1 & N0 & M0 \\
Stage IIA & T2 & N0 & M0 \\
Stage IIB & T3 & N0 & M0 \\
Stage IIIA & T4 & N0 & M0 \\
Stage IIIB & Any T & N1 & M0 \\
Stage IV & Any T & Any N & M1 \\
\hline
\end{tabular}

TNM, tumor, node, metastasis.

Adapted from American Joint Committee on Cancer (AJCC) Cancer Staging Manual. 8th ed. ${ }^{11}$

amongst all anatomical site groups at 24.6 years. ${ }^{5}$ This is likely due to the fact that a majority of these lesions are discovered at low grades, often incidentally on screening colonoscopy. Survival for high grade rectal NETs on the other hand decreases from $91 \%$ for G1 to $32 \%$ for G3 at 5 years, highlighting a significant malignant potential if not adequately resected in a timely fashion. ${ }^{4} \mathrm{~A}$ large prospective study of prognostic features of rectal NETs in 347 patients reported that risk factors for metastasis include increasing tumor size, increased mitotic rate, lymphovascular invasion, and depression or ulceration seen macroscopically on endoscopy. None of the patients with tumor size $\leq 10 \mathrm{~mm}$ had metastatic disease. $^{12}$ The metastatic potential of rectal NETs $<10 \mathrm{~mm}$ has been reported to be as low as $2 \%$, increasing to
$10 \%-15 \%$ in tumors ranging from $1-2 \mathrm{~cm}$ and $60 \%-80 \%$ in tumors $>2.0 \mathrm{~cm}$ in size. ${ }^{13}$

\section{DIAGNOSIS}

When biopsies are obtained prior to tumor resection or a rectal NET is suspected on endoscopy, EUS can play a major role in pre-operative planning. EUS is an endoscope with a high frequency ultrasound at the tip, allowing for visualization of the histological layers of the luminal walls of the gastrointestinal tract. ${ }^{14}$ Rectal NETs appear as smooth, hypoechoic, submucosal lesions on EUS imaging. ${ }^{15}$ According to the European Neuroendocrine Tumor Society consensus guidelines, EUS is recommended to assess tumor size, depth of invasion, and the presence of lymph node involvement in order to determine the appropriate subsequent intervention (Fig. 2). ${ }^{3}$ In a study performed by Kobayashi et al., EUS correctly imaged the size and depth of fifty-two out of fifty-three lesions (98\%), and these results were consistent with the histopathologic findings of the resected specimens. ${ }^{16}$ EUS could accurately diagnose the depth of lesions as small as $2 \mathrm{~mm}$ in diameter. ${ }^{16}$ These results were corroborated in a 2017 study by Park et al., which demonstrated that EUS-determined size correlated well with both endoscopic and histologic estimation. ${ }^{17}$ EUS accuracy in determining depth of invasion was reported to be $92.5 \% .{ }^{17}$ Yet another study reported that pre-operative depth determination by EUS was $100 \%{ }^{18}$ As expected, a higher pathologic complete resection rate was shown to be associated with the use of EUS by univariate analysis. ${ }^{19}$ EUS is also useful to assess for local lymph node invasion, to rule out invasion beyond the muscularis propria, and to search for residual tumor after incidental resection. ${ }^{15,20}$ All of these tumor factors play a major role in determining the method of endoscopic resection indicated, or whether aggressive surgery should be considered. Thus, EUS plays an important role in determining the appropriate course of management.

\section{MANAGEMENT}

The current published guidelines recommend local endoscopic resection for rectal NETs $\leq 10 \mathrm{~mm}$ in size with no risk factors for metastasis. However, no clear indications for type of endoscopic intervention exist. One study suggested that rectal NETs $\leq 10 \mathrm{~mm}$ without invasion of the muscularis propria and without depression or ulceration seen macroscopically could be locally resected safely. ${ }^{16}$ Rectal NETs between 10-20 $\mathrm{mm}$ have sparked more controversy and can 

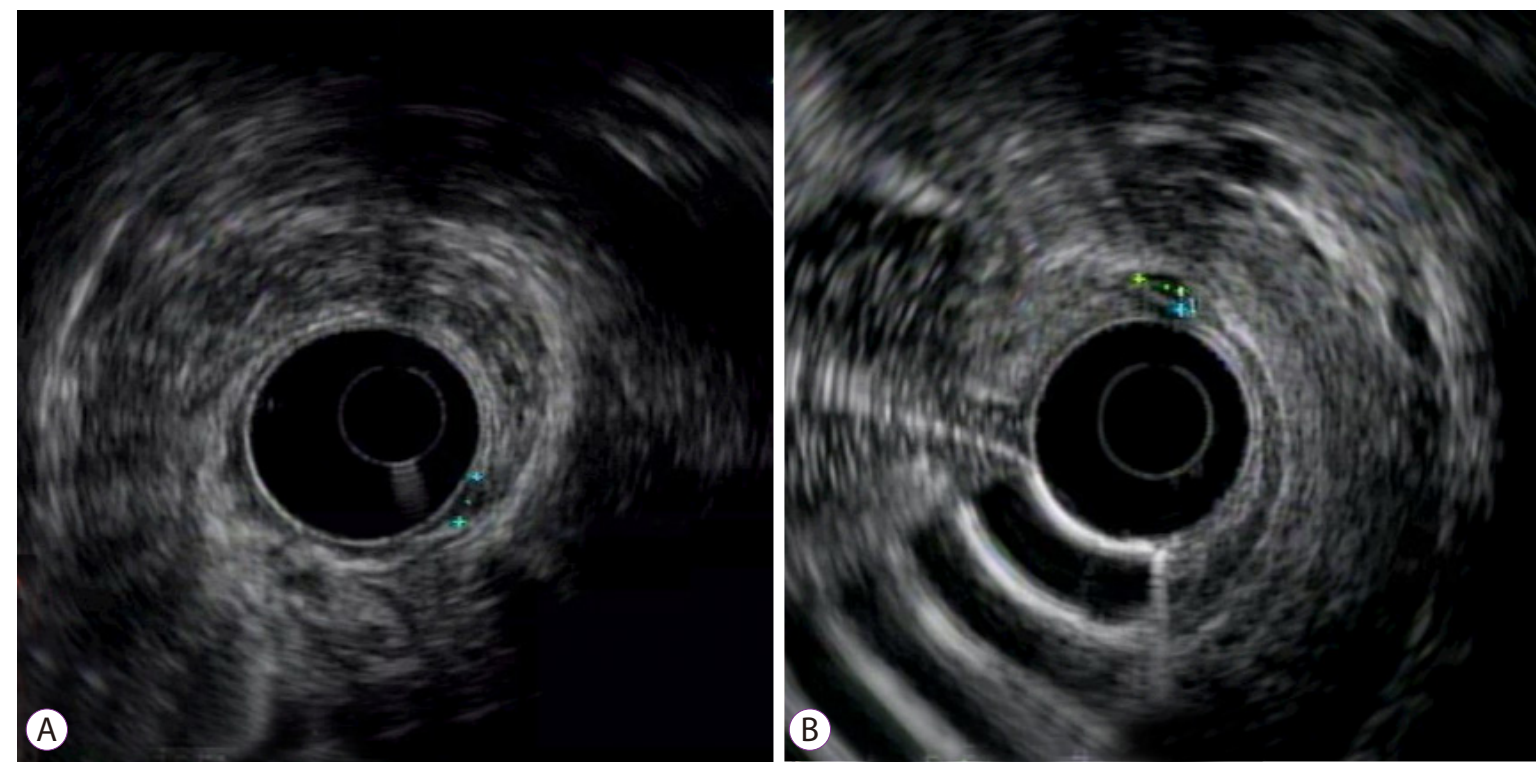

Fig. 2. Radial endosonographic findings of rectal neuroendocrine tumors. (A) and (B) show small homogeneous hypoechoic lesions connected with deep mucosal layer.

be managed with endoscopy or surgery depending on stage/ grade. Alternatively, larger lesions $>20 \mathrm{~mm}$ should managed like rectal adenocarcinoma with low anterior resection, or in rare cases, abdominoperineal resection. ${ }^{3}$

Conventional polypectomy has shown to be an ineffective form of treatment for rectal NETs as most of these lesions extend into the submucosa. Some studies have reported that the complete resection rate of conventional polypectomy was as low as $20 \%-30 \%{ }^{19,21}$ Similarly, piecemeal biopsy removal of rectal NETs are not recommended due to limitations of histological assessment of lateral and deep margins that affect complete resection rates. Several therapeutic options have become popular for endoscopic resection of rectal NETs $\leq 10$ $\mathrm{mm}$, including endoscopic mucosal resection (EMR), modified EMR (m-EMR) such as band ligation, and endoscopic submucosal dissection (ESD). Many rectal NETs are often incidental findings and are diagnosed retrospectively after lesion excision, despite some atypical features on endoscopy such as a semi-pedunculated appearance, hyperemia, central depression, erosion, and ulceration. ${ }^{7,22}$ No consensus exists as to the best course of endoscopic management for these patients.

To overcome the limitations of standard polypectomy, many advanced techniques have been created such as EMR, $\mathrm{m}$-EMR, and ESD. The appropriate therapeutic intervention is chosen to maximize the likelihood that the entire NET has been excised with clear resection margins (both lateral and deep) with no residual tumor left behind. Conventional EMR confers an advantage over standard polypectomy as submucosal injection creates a peduncle, lifting the tumor away from the muscularis propria and allowing for simple resection using snare cautery. ${ }^{15}$ However, studies have shown that conventional EMR has variable complete resection rates as confirmed by endoscopy and histology, ranging from $30 \%-70 \%{ }^{23-27}$ Furthermore, the curative resection rate (as defined by a $<10 \mathrm{~mm}$ NET with invasion limited to the submucosal layer without lymphovascular invasion and clear resection margins) for conventional EMR was reported to be as low as $27.3 \%$ in a study by Nakamura et al. in $2016 .{ }^{25}$ Many of these patients had residual tumor at the resection site or experienced local recurrence during follow-up and required re-intervention. ${ }^{23,28,29}$ Although conventional EMR may be useful for smaller rectal NETs $<5 \mathrm{~mm}$ in size, ${ }^{15}$ alternative advanced endoscopic strategies have wider applicability.

Like EMR, ESD also employs a submucosal injection to lift the rectal NET away from the muscularis propria layer. However, a knife is used to dissect around the entire lesion in the submucosal plane, using coagulation after resection to ensure hemostasis and prevent delayed bleeding. ${ }^{23}$ This results in a high en bloc resection rate, approximately 80\%$100 \%{ }^{30-32}$ Histologic evaluation of these lesions is of higher yield because the whole tumor is present, as opposed to piecemeal resection achieved with conventional EMR. In a series of meta-analyses, ESD was consistently shown to have a higher complete resection rate than EMR as confirmed by both endoscopy as well as histology. ${ }^{28,29,33-35}$ However, ESD is associated with a higher rate of complications and adverse events than EMR. Bowel perforation as a result of ESD has been reported in multiple studies. ${ }^{25,28,30,32}$ In addition, patients are at risk for developing delayed bleeding post-proce- 

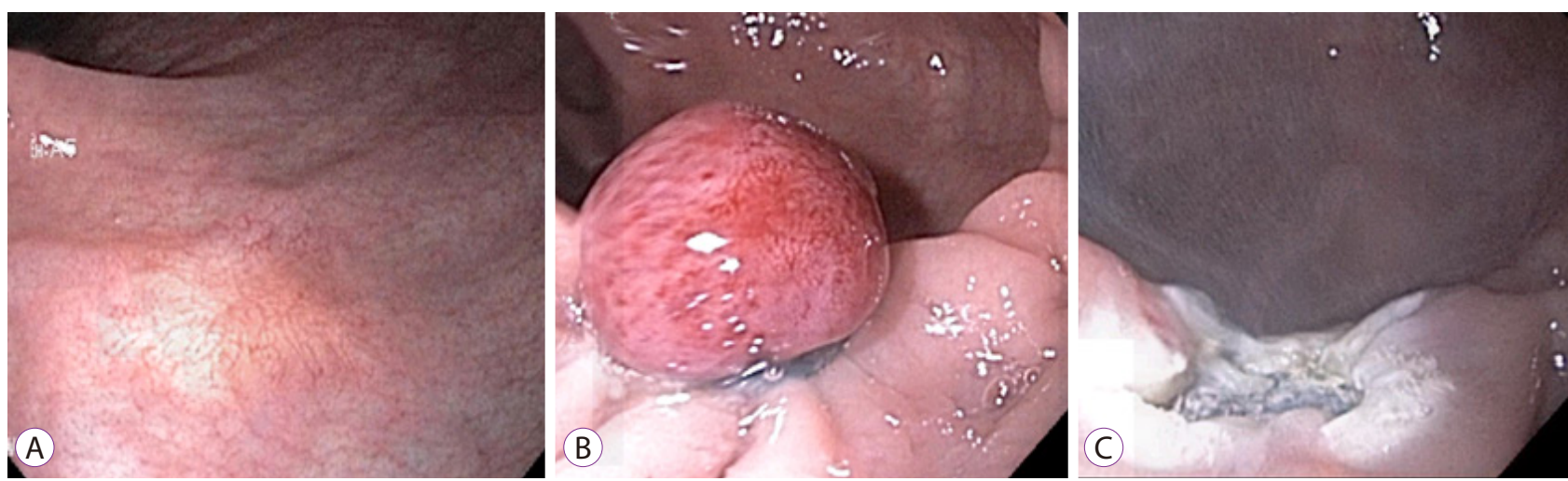

Fig. 3. Endoscopic mucosal resection with band ligation of rectal neuroendocrine tumor. (A) Rectal neuroendocrine tumor. (B) Band applied to tumor. (C) Status post resection.

Table 2. Comparison of Rectal Neuroendocrine Tumor Resection Techniques

\begin{tabular}{|c|c|c|c|}
\hline Technique & Advantages & Disadvantages & Patient selection \\
\hline Standard polypectomy & $\begin{array}{l}\text { Simple technique, low risk } \\
\text { of complication, decreased } \\
\text { procedural time }\end{array}$ & High rate of incomplete resection & $<5 \mathrm{~mm}$, confined to mucosa \\
\hline EMR & $\begin{array}{l}\text { Simple technique, low risk } \\
\text { of complication, decreased } \\
\text { procedural time }\end{array}$ & $\begin{array}{l}\text { Variable rate of completion resection } \\
(30 \%-70 \%)\end{array}$ & $<5 \mathrm{~mm}$ \\
\hline ESD & $\begin{array}{l}\text { High complete/en-bloc resection } \\
\text { rate }(80 \%-100 \%)\end{array}$ & $\begin{array}{l}\text { Increased length of procedure, } \\
\text { Increased complications } \\
\text { (perforation, delayed bleeding), } \\
\text { Increased cost and length of hospital } \\
\text { stay }\end{array}$ & $>10 \mathrm{~mm}$, deeper $\mathrm{T} 1$ lesions \\
\hline m-EMR & $\begin{array}{l}\text { Complete/en-bloc resection rates } \\
\text { comparable with ESD for smaller } \\
\text { lesions, short procedural time, } \\
\text { outpatient procedure }\end{array}$ & $\begin{array}{l}\text { Bleeding and perforation rates are } \\
\text { higher than standard EMR; local } \\
\text { recurrence in lesions }>10 \mathrm{~mm} \text { for } \\
\text { EMR-C technique }\end{array}$ & $<10 \mathrm{~mm}$ \\
\hline Low anterior resection & Complete resection & Increased morbidity & Invasion of muscularis propria \\
\hline $\begin{array}{l}\text { Transanal Endoscopic } \\
\text { Microsurgery }\end{array}$ & $\begin{array}{l}\text { Allows for full thickness excision, } \\
\text { access to higher lesions in the } \\
\text { rectum, can be used as salvage } \\
\text { therapy }\end{array}$ & Increased morbidity & $\begin{array}{l}>10 \mathrm{~mm} \text { confined to } \\
\text { submucosa, }<10 \mathrm{~mm} \text { with } \\
\text { invasion into muscularis } \\
\text { propria without nodal } \\
\text { involvement }\end{array}$ \\
\hline
\end{tabular}

EMR, endoscopic mucosal resection; ESD, endoscopic submucosal dissection; m-EMR, modified EMR; EMR-C, EMR with cap aspiration.

dure. $25,2,6,28,32,34,36,37$ ESD also has longer reported procedure duration than conventional EMR, and is often only performed at tertiary care centers by expert providers trained to perform this procedure. ${ }^{29,33}$

Despite the advantages of ESD with higher complete and en-bloc resection rates as compared with EMR, the numerous adverse events and technical difficulties have led to the development of $\mathrm{m}$-EMR procedures. $\mathrm{m}$-EMR includes endoscopic submucosal resection with band ligation (ESMR-L), EMR with cap aspiration (EMR-C), circumferential incision EMR, and two-channel EMR, among other modifications.
A meta-analyses of ten retrospective studies found complete resection rates of rectal NETs were comparable between $\mathrm{m}$-EMR and ESD. ${ }^{28}$ Another meta-analyses corroborated these findings, showing a significantly higher rate of complete histologic resection using both ESD and m-EMR as compared with conventional EMR. ${ }^{34}$

ESMR-L is one of the most studied types of m-EMR. ESMR-L differs from EMR as the lesion is aspirated into a ligator device and an elastic band is deployed prior to snare resection (Fig. 3) ${ }^{38}$ In a study by Mashimo et al., the complete histologic resection rate using ESMR-L was 95.2\%, which 
approaches the rates reported for ESD. ${ }^{39}$ The curative resection rate with ESMR-L also approached that of ESD, and in one study that compared ESMR-L to ESD and EMR, none of the patients who underwent resection with ESMR-L had any residual tumor. ${ }^{23}$ En bloc resection rate with ESMR-L has been reported to be as high as $100 \%$ in another study. ${ }^{40}$ Mean hospitalization time was shorter with ESMR-L, and many cases could be performed on an outpatient basis with shorter procedure time..$^{40}$ However, as with ESD, complications including bleeding and perforation were also reported with ESMR-L, more frequently than conventional EMR. ${ }^{23,41}$

Other m-EMR have shown some promise as well. EMR-C, or cap-assisted EMR was reported to have a similar resection rate and frequency of adverse events as ESD, but with the advantage of shorter procedure time. ${ }^{24}$ However, for lesions close to or slightly larger than $10 \mathrm{~mm}$ in diameter, $16 \%$ of patients experienced local recurrence after EMR-C as compared with 0 patients who underwent ESD. ${ }^{42}$ Table 2 compares all rectal NET resection techniques.

Since many rectal NETs are discovered incidentally, clean resection margins are difficult to obtain as standard polypectomy does not adequately reach the submucosa. These patients, along with cases who fail to achieve clear resection margins with more advanced endoscopic interventions, should be considered for salvage therapy. The appropriate salvage therapy has not been elucidated. EUS can be used to evaluate the residual tumor remaining, and rectal NETs with high-risk features (larger primary tumor size, grade $\geq 2$, presence of lymphovascular invasion, and margin involvement) should be considered for alternative intervention such as transanal endoscopic microsurgery or more aggressive surgery, ${ }^{8,1520}$ For smaller rectal NETs, repeat endoscopic intervention can be used. ESD is a potential option, but data for salvage therapy is limited. One study showed that EMR-C could be helpful in cases where conventional EMR cannot be used secondary to fibrosis at the previous resection site. A $100 \%$ complete resection rate was confirmed, and patients were negative for recurrence after 1 year. ${ }^{43}$

The published long term outcomes for patients with endoscopic resection of rectal NETs have been promising. One article published in 2015 reported no metastasis or recurrence of disease at a median follow-up of 67.5 months for tumors sized 2-13 mm. ${ }^{44}$ Another study by Chen et al. focused on outcomes after 2 years post-ESD for tumors $<20$ $\mathrm{mm}$ in size. ${ }^{31}$ None of the 239 patients experienced disease recurrence, although 6 (2.51\%) of them did have distant metastasis. Interestingly, the tumor sizes of these 6 patients varied from 5-15 mm, demonstrating that even small primary rectal NETs can be associated with metastatic disease. ${ }^{31}$

\section{CONCLUSIONS}

Given the limitations of conventional polypectomy, a plethora of minimally invasive endoscopic interventions for resection of rectal NETs have emerged. However, there remains a relative paucity of robust literature comparing these interventions in the management of rectal NETs. Furthermore, much of the existing literature boasts conflicting data. It is clear that EUS plays an important role in assessing tumor burden, characteristics, and lymph node metastasis. As such, it should be used to guide further management once rectal NETs have been diagnosed. EMR should be favored against as it has variable resection rates, although it can be considered for rectal NETs of diminutive size. ESD and $\mathrm{m}$-EMR both demonstrate higher complete resection rates, but complications and the need for technical expertise for ESD remain limiting factors. Prospective studies are needed to adequately compare the endoscopic intervention options available and their effects on patient outcomes.

\section{Conflicts of Interest}

The authors have no financial conflicts of interest.

\section{REFERENCES}

1. Yao JC, Hassan M, Phan A, et al. One hundred years after "carcinoid": epidemiology of and prognostic factors for neuroendocrine tumors in 35,825 cases in the United States. J Clin Oncol 2008;26:3063-3072.

2. Fraenkel M, Kim M, Faggiano A, de Herder WW, Valk GD. Incidence of gastroenteropancreatic neuroendocrine tumours: a systematic review of the literature. Endocr Relat Cancer 2014;21:R153-R163.

3. Caplin M, Sundin A, Nillson O, et al. ENETS consensus guidelines for the management of patients with digestive neuroendocrine neoplasms: colorectal neuroendocrine neoplasms. Neuroendocrinology 2012;95:8897.

4. Modlin IM, Lye KD, Kidd M. A 5-decade analysis of 13,715 carcinoid tumors. Cancer 2003;97:934-959.

5. Dasari A, Shen C, Halperin D, et al. Trends in the incidence, prevalence, and survival outcomes in patients with neuroendocrine tumors in the United States. JAMA Oncol 2017;3:1335-1342.

6. Rindi G, Petrone G, Inzani F. The 2010 WHO classification of digestive neuroendocrine neoplasms: a critical appraisal four years after its introduction. Endocr Pathol 2014;25:186-192.

7. Shim KN, Yang SK, Myung SJ, et al. Atypical endoscopic features of rectal carcinoids. Endoscopy 2004;36:313-316.

8. Anthony LB, Strosberg JR, Klimstra DS, et al. The NANETS consensus guidelines for the diagnosis and management of gastrointestinal neuroendocrine tumors (nets): well-differentiated nets of the distal colon and rectum. Pancreas 2010;39:767-774.

9. Mandair D, Caplin ME. Colonic and rectal NET's. Best Pract Res Clin Gastroenterol 2012;26:775-789.

10. Weinstock B, Ward SC, Harpaz N, Warner RR, Itzkowitz S, Kim MK. Clinical and prognostic features of rectal neuroendocrine tumors. Neuroendocrinology 2013;98:180-187.

11. American Joint Committee on Cancer (AJCC). Cancer staging manual [Internet]. Chicago (IL): American Joint Committee on Cancer (AJCC); c2016 [cited 2017 Aug 22]. Available from: https://cancerstaging.org/ 
references-tools/deskreferences/Pages/default.aspx.

12. Park CH, Cheon JH, Kim JO, et al. Criteria for decision making after endoscopic resection of well-differentiated rectal carcinoids with regard to potential lymphatic spread. Endoscopy 2011;43:790-795.

13. Mani S, Modlin IM, Ballantyne G, Ahlman H, West B. Carcinoids of the rectum. J Am Coll Surg 1994;179:231-248.

14. Fusaroli P, Caletti G. Endoscopic ultrasonography: current clinical role. Eur J Gastroenterol Hepatol 2005;17:293-301.

15. Basuroy R, Haji A, Ramage JK, Quaglia A, Srirajaskanthan R. Review article: the investigation and management of rectal neuroendocrine tumours. Aliment Pharmacol Ther 2016;44:332-345.

16. Kobayashi K, Katsumata T, Yoshizawa S, et al. Indications of endoscopic polypectomy for rectal carcinoid tumors and clinical usefulness of endoscopic ultrasonography. Dis Colon Rectum 2005;48:285-291.

17. Park SB, Kim DJ, Kim HW, et al. Is endoscopic ultrasonography essential for endoscopic resection of small rectal neuroendocrine tumors? World J Gastroenterol 2017;23:2037-2043.

18. Ishii N, Horiki N, Itoh T, et al. Endoscopic submucosal dissection and preoperative assessment with endoscopic ultrasonography for the treatment of rectal carcinoid tumors. Surg Endosc 2010;24:1413-1419.

19. Son HJ, Sohn DK, Hong CW, et al. Factors associated with complete local excision of small rectal carcinoid tumor. Int J Colorectal Dis 2013;28:57-61.

20. de Mestier L, Brixi H, Gincul R, Ponchon T, Cadiot G. Updating the management of patients with rectal neuroendocrine tumors. Endoscopy 2013;45:1039-1046

21. Onozato Y, Kakizaki S, lizuka H, Sohara N, Mori M, Itoh H. Endoscopic treatment of rectal carcinoid tumors. Dis Colon Rectum 2010;53:169176.

22. Kim BN, Sohn DK, Hong CW, et al. Atypical endoscopic features can be associated with metastasis in rectal carcinoid tumors. Surg Endosc 2008;22:1992-1996.

23. Kim KM, Eo SJ, Shim SG, et al. Treatment outcomes according to endoscopic treatment modalities for rectal carcinoid tumors. Clin Res Hepatol Gastroenterol 2013;37:275-282.

24. Yang DH, Park Y, Park SH, et al. Cap-assisted EMR for rectal neuroendocrine tumors: comparisons with conventional EMR and endoscopic submucosal dissection (with videos). Gastrointest Endosc 2016;83:10151022; quiz 1023-.e6.

25. Nakamura K, Osada M, Goto A, et al. Short- and long-term outcomes of endoscopic resection of rectal neuroendocrine tumours: analyses according to the WHO 2010 classification. Scand J Gastroenterol 2016;51:448-455.

26. Jeon JH, Cheung DY, Lee SJ, et al. Endoscopic resection yields reliable outcomes for small rectal neuroendocrine tumors. Dig Endosc 2014;26:556-563.

27. Kim HH, Park SJ, Lee SH, et al. Efficacy of endoscopic submucosal resection with a ligation device for removing small rectal carcinoid tumor compared with endoscopic mucosal resection: analysis of 100 cases. Dig Endosc 2012;24:159-163.

28. Zhou X, Xie H, Xie L, Li J, Cao W, Fu W. Endoscopic resection therapies for rectal neuroendocrine tumors: a systematic review and meta-analysis. J Gastroenterol Hepatol 2014;29:259-268.

29. Zhang HP, Wu W, Yang S, Lin J. Endoscopic treatments for rectal neu- roendocrine tumors smaller than $16 \mathrm{~mm}$ : a meta-analysis. Scand J Gastroenterol 2016;51:1345-1353.

30. Zhou PH, Yao LQ, Qin XY, et al. Advantages of endoscopic submucosal dissection with needle-knife over endoscopic mucosal resection for small rectal carcinoid tumors: a retrospective study. Surg Endosc 2010;24:2607-2612.

31. Chen T, Yao LQ, Xu MD, et al. Efficacy and safety of endoscopic submucosal dissection for colorectal carcinoids. Clin Gastroenterol Hepatol 2016;14:575-581.

32. Park HW, Byeon JS, Park YS, et al. Endoscopic submucosal dissection for treatment of rectal carcinoid tumors. Gastrointest Endosc 2010;72:143-149.

33. Zhong DD, Shao LM, Cai JT. Endoscopic mucosal resection vs endoscopic submucosal dissection for rectal carcinoid tumours: a systematic review and meta-analysis. Colorectal Dis 2013;15:283-291.

34. He L, Deng T, Luo H. Efficacy and safety of endoscopic resection therapies for rectal carcinoid tumors: a meta-analysis. Yonsei Med J 2015;56:72-81.

35. Lee DS, Jeon SW, Park SY, et al. The feasibility of endoscopic submucosal dissection for rectal carcinoid tumors: comparison with endoscopic mucosal resection. Endoscopy 2010;42:647-651.

36. Park SB, Kim HW, Kang DH, Choi CW, Kim SJ, Nam HS. Advantage of endoscopic mucosal resection with a cap for rectal neuroendocrine tumors. World J Gastroenterol 2015;21:9387-9393.

37. Choi CW, Kang DH, Kim HW, et al. Comparison of endoscopic resection therapies for rectal carcinoid tumor: endoscopic submucosal dissection versus endoscopic mucosal resection using band ligation. J Clin Gastroenterol 2013;47:432-436.

38. Ono A, Fujii T, Saito Y, et al. Endoscopic submucosal resection of rectal carcinoid tumors with a ligation device. Gastrointest Endosc 2003;57:583-587.

39. Mashimo Y, Matsuda T, Uraoka T, et al. Endoscopic submucosal resection with a ligation device is an effective and safe treatment for carcinoid tumors in the lower rectum. J Gastroenterol Hepatol 2008;23:218221.

40. Niimi K, Goto O, Fujishiro M, et al. Endoscopic mucosal resection with a ligation device or endoscopic submucosal dissection for rectal carcinoid tumors: an analysis of 24 consecutive cases. Dig Endosc 2012;24:443-447.

41. Bang BW, Park JS, Kim HK, Shin YW, Kwon KS, Kim JM. Endoscopic resection for small rectal neuroendocrine tumors: comparison of endoscopic submucosal resection with band ligation and endoscopic submucosal dissection. Gastroenterol Res Pract 2016;2016:6198927.

42. Wang X, Xiang L, Li A, et al. Endoscopic submucosal dissection for the treatment of rectal carcinoid tumors $7-16 \mathrm{~mm}$ in diameter. Int J Colorectal Dis 2015;30:375-380.

43. Jeon SM, Lee JH, Hong SP, Kim TI, Kim WH, Cheon JH. Feasibility of salvage endoscopic mucosal resection by using a cap for remnant rectal carcinoids after primary EMR. Gastrointest Endosc 2011;73:1009-1014.

44. Sekiguchi M, Sekine S, Sakamoto T, et al. Excellent prognosis following endoscopic resection of patients with rectal neuroendocrine tumors despite the frequent presence of lymphovascular invasion. J Gastroenterol 2015;50:1184-1189. 